\title{
Shunt Compensaton of the Integrated Nigeria's 330KV Transimission Grid System
}

\author{
Engr. Obi, Fortunatus Uche ${ }^{1}$, Aghara, Jachimma² And Prof. Atuchukwu John ${ }^{3}$ \\ ${ }^{1}$ Dept of Electrical Electronics Engineering Technology, Metallurgical Training Institute, Onitsha \\ ${ }^{2}$ Dept of Electrical Engineering, Nnamdi Azikiwe University, Awka \\ ${ }^{31}$ Dept of Electrical Electronics Engineering, Chukwuemeka Odumegwu Ojukwu University, Uli
}

\begin{abstract}
The Nigerian Power system is complex and dynamic, as a result of this it is characterized by frequent faults and outages resulting to none steady supply of power to the teaming consumers. This has great effect on the activities and mode of living of Nigerians. The research work was carried out on contingency analysis on the existing integrated $330 \mathrm{KV}$ Nigeria grid system and to carry out a shunt compensation on the violated buses, the shutdown of Eket-Ibom line being the case study so as to determine the following; uncertainties and effects of changes in the power system, to recognize limitations that can affect the power reliability and minimize the sudden increase or decrease in the voltage profile of the buses through shunt compensation of buses. Determine tolerable voltages and thermal violation of $+5 \%$ and $-5 \%$ of base voltage $330 \mathrm{KV}(\mathbf{0 . 9 5 - 1 . 0 5 )} \mathrm{PU}$ and to determine the critical nature and importance of some buses. This is aimed at bridging the gap of proposing further expansion of the grid system which is not only limited by huge sum of finance and difficulties in finding right of- way for new lines but also which faces the challenges of fixed land and longtime of construction. The data of the network was gotten and modeled. The power flow and contingency analysis of the integrated Nigeria power system of 51 buses (consisting of 16 generators and 35 loads) and 73 transmission lines were carried out using Newton-Raphson Load Flow (NRLF) method in Matlab environment, simulated with PSAT software. Shunt compensation of the weak buses were done using Static Var Compensator (SVC) with Thyristor Controlled Reactor- Fixed capacitor (TCR-FC) technique. Results obtained showed that the average voltage for base simulation was $326.25 \mathrm{KV}$, contingency 323.67KV and compensation was $322.37 \mathrm{KV}$. Voltage violations for lower limit were observed at Itu as 309K V and Eket as 306.81 KV while violations for upper limit were recorded at Damaturu as $352.85 \mathrm{KV}$, Yola as 353.62 KV, Gombe as 355.98KV, and Jos as 342.97 KV. However after shunt compensation there were improvements for the violations at lower limits and that of higher limit were drastically brought down as recorded below: Damaturu 329.93 KV, Jos $330 \mathrm{KV}$, Eket 327.2 KV, Gombe 333.55KV, Itu 330KV, and Yola 330.52KV
\end{abstract}

Keywords:- Contingency, FACTS Controllers, Power flow study, Shunt Compensation.

\section{INTRODUCTION}

The power system is dynamic, new sources of power are added to the Nigeria's power system, an over-riding factor in the Operation of the power system is the desire to maintain security and expectable reliability level in all sectors -generation, transmission, and distribution (Madueme and Nnonyelu, 2013)

The goal of a power-flow study is to obtain complete voltages angle and magnitude information for each bus in a power system for specified load and generator real power and voltage conditions (Grainger and Stervenson, 1994)

The contingency analysis of the power system using load flow method would enable the planning authority to plan for and make provision for further expansions of the grid system. The result of this analysis will be used to determine the security level of the Nigeria power system and suggestions will also be made on the level of protection to be applied on the Nigeria power system with aim of improving system security (Onojo, et al, 2013).

Flexible AC transmission systems or FACTS are devices which allow the flexible and dynamic control of power systems. . Flexible Alternating Current Transmission System (FACTS) is static equipment used for the AC transmission of electrical energy. It is meant to enhance controllability and increase power transfer capability. It is generally power electronics based device.

The data of the network was gotten and modeled. The power flow and contingency analysis of the integrated Nigeria power system of 51 buses (consisting of 16 generators and 35 loads) and 73 transmission lines were carried out using Newton-Raphson Load Flow (NRLF) method in Matlab environment, simulated with PSAT software. Shunt compensation of the weak areas was done using Static Var Compensator (SVC) with Thyristor Controlled Reactor- Fixed capacitor (TCR-FC). The result of the base simulation employing violation limits of $+5 \%$ and $-5 \%$ of base voltage $330 \mathrm{KV}$ 


\section{MATERIAL AND METHODS}

\section{Shunt compensation}

Shunt compensation (inductive compensation)-This is the compensation normally carried out as a result of the long length of the transmission lines in order to limit the line voltage.

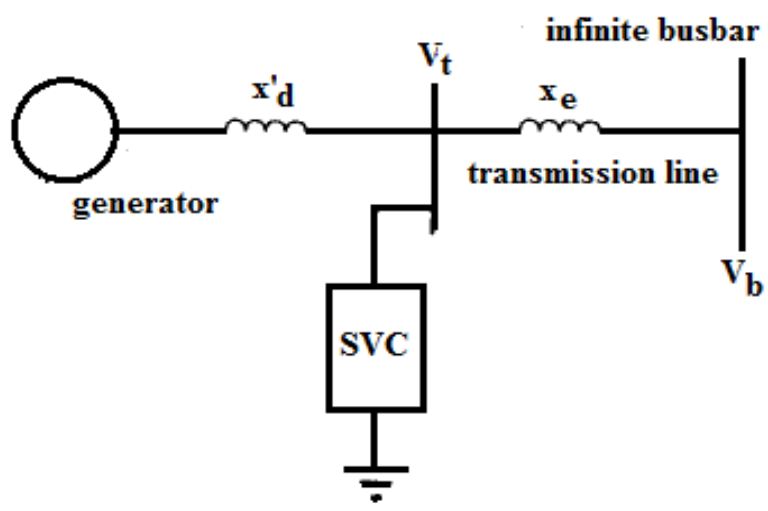

Fig 1:- Connection of SVC to the Bus

The SVC is a shunt device of the FACTS family using power electronics to control power flow and improve transient stability on power grids. It has been used for reactive power compensation since the mid-1970, firstly for arc furnace flicker compensation and then in power transmission systems. One of the first 40 MVARs SVC was installed at the Shannon Substation of the Minnesota Power and Light system in 1978 (Boudjella Houari and F.Z Gherbi, 2008)

Components of a static VAR system may include: Transformer between high voltage (HV) network bus and the medium voltage (MV) bus where power electronic equipment is connected. Usually a dedicated transformer is used, but sometimes the tertiary of an autotransformer is used. Thyristor-controlled reactors (TCRs) connected to medium voltage bus. Thyristor-switched reactors (TSRs) connected to medium voltage bus. Thyristor-switched capacitors (TSCs) connected to the medium voltage bus. Saturated reactor (SR) connected to the medium Voltage bus. Fixed capacitors (FC), harmonic filters connected to the medium voltage bus. At fundamental frequency, the filters are capacitive. Mechanically-switched capacitors (MSCs) or reactors (MSRs) usually connected at a high voltage bus, Control system, usually with a primary function of regulating the transmission voltage. (IEE special Stability control working group, 1994).

(SVC) using Thyristor controlled Reactor with fixed capacitor (TCR-FC) technique for shunt compensation, an indebt study and analysis of the SVC was carried out, results were obtained

\section{Modeling of SVC in TCR- FC Configuration}

The particular SVC modeled in this work consists of a thyristor controlled reactor (TCR) stage to provide the lagging vars and a fixed capacitor FC which offers the leading vars. The lagging reactive power (inductive reactive power) and TCR current amplitude can be controlled continuously by varying the thyristor firing angle between 90 and 180. The TCR firing angle can be fully changed within one cycle of the fundamental frequency, thus providing smooth and fast control of reactive power supplied to the system, (Sankarbabu, P. and Subrahmanyam, J.B.V.2010) and (Oltean, S.E. 2012),

The leading vars (capacitive reactive power) are usually provided by a different number of capacitor bank units. By combining these two components, fixed capacitor and continuously controlled reactor, a smooth variation in reactive power over the entire range can be achieved and reactance that can perform both inductive and capacitive compensation. The reactive power Injection of a SVC connected to a bus bar and the total shunt admittance of the SVC are given by:

$\mathrm{Q}_{\mathrm{SCV}}=-\mathrm{B}_{\mathrm{SCV}} \cdot \mathrm{V}^{2}$

$\mathrm{B}_{\mathrm{SVC}}=\mathrm{B}_{\mathrm{C}}-\mathrm{B}_{\mathrm{L}}$

1

In (1) $Q_{S V C}$ is the reactive power injection of the SVC (TCR-FC type), $B_{S V C}$, the admittance of the SVC, $B_{C}$ the constant admittance of the fixed capacitor and $B_{L}$ the variable admittance of the thyristor controlled reactor. For a TCR-FC compensator the admittance depends on firing angle $\alpha$ ( Karpagam, N., and Devaraj, D. (2009), and ( Oltean, S.E. (2012),

$$
\begin{aligned}
\mathrm{B}_{\mathrm{SVC}} & =\frac{1}{\mathrm{XC}}-B L \\
\mathrm{~B}_{\mathrm{L}}(\alpha) & =\frac{2 \pi-2 \alpha+\operatorname{Sin}(2 \alpha)}{\pi X L}
\end{aligned}
$$

The inductive and capacitive reactances are $\mathrm{X}_{\mathrm{L}}$ and $\mathrm{Xc}$ respectivelyThe static VAR compensator will be located at the generator busbar to provide significant damping during transient condition

\section{Modelling of the Power system}

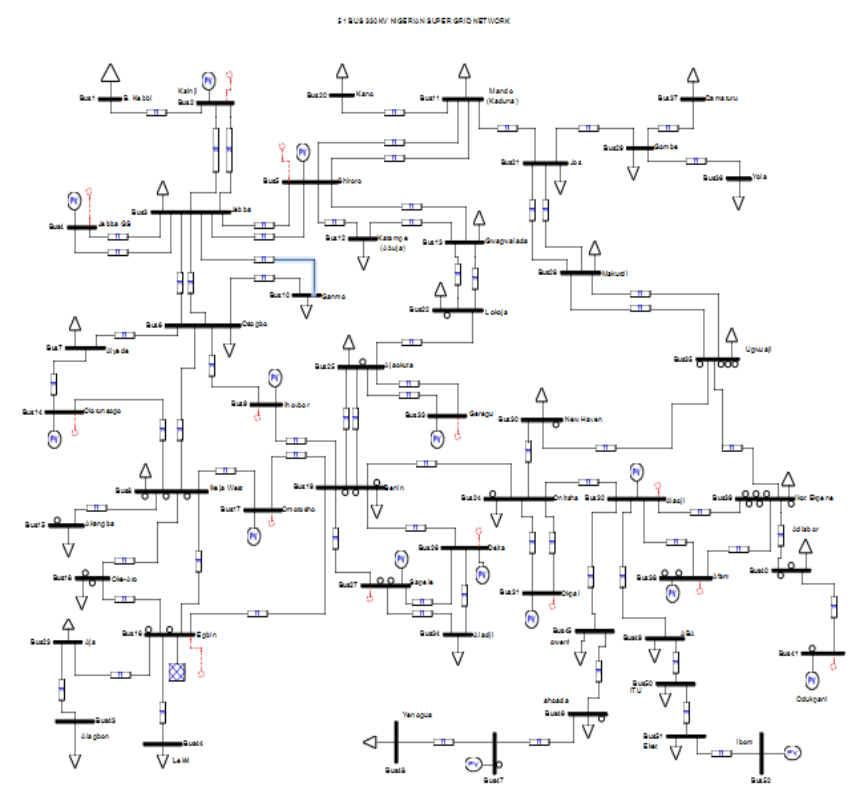

Fig 2:- Modelled the Power system 


\section{RESULTS}

Table of the Base simulation, Contingency and compensation

\begin{tabular}{|c|c|c|c|}
\hline Bus Name & $\begin{array}{c}\text { Voltage (base } \\
\text { case) }\end{array}$ & $\begin{array}{c}\text { Voltage } \\
\text { (contingency) }\end{array}$ & $\begin{array}{c}\text { Voltage } \\
\text { (compensation) }\end{array}$ \\
\hline B. Kebbi & 318.6460574 & 318.6460574 & 318.6460574 \\
\hline Ganmo & 325.4356264 & 327.8912833 & 327.8757691 \\
\hline Mando & 325.7830219 & 331.0310991 & 327.3041197 \\
\hline katampe & 318.2364991 & 319.6817713 & 319.5944518 \\
\hline Gwagwalada & 317.2035134 & 318.9370315 & 318.8319046 \\
\hline olorunsango & 317.13 & 317.13 & 317.13 \\
\hline Akangba & 318.3432778 & 321.819568 & 321.7779874 \\
\hline Egbin & 340.23 & 340.23 & 340.23 \\
\hline Omotosho & 330 & 330 & 330 \\
\hline Oke-Aro & 322.0323381 & 324.8830914 & 324.8491353 \\
\hline Benin & 314.2040674 & 323.1837666 & 322.8124964 \\
\hline Kainji & 330 & 330 & 330 \\
\hline Kano & 321.9708864 & 327.3193232 & 323.5213541 \\
\hline Jos & 325.5346997 & 347.9693323 & 330 \\
\hline lokoja & 315.9153175 & 319.1542851 & 318.9731119 \\
\hline aja & 338.4843857 & 338.4843857 & 338.4843857 \\
\hline Onitcha & 320.9685188 & 328.7579784 & 327.7807504 \\
\hline Ajaokuta & 317.8304854 & 321.6971946 & 321.5022359 \\
\hline Delta & 339.57 & 339.57 & 339.57 \\
\hline sapele & 339.57 & 339.57 & 339.57 \\
\hline Markurdi & 318.6684115 & 341.0906472 & 330.4367224 \\
\hline Gombe & 327.5563674 & 355.9846032 & 333.5598267 \\
\hline Jebba & 336.9075027 & 337.2986525 & 337.2975932 \\
\hline New Haven & 315.498963 & 330.5890307 & 326.2109564 \\
\hline okpai & 333.96 & 333.96 & 333.96 \\
\hline Alaoji & 330 & 330 & 330 \\
\hline Geregu & 330 & 330 & 330 \\
\hline aladji & 336.5710723 & 336.5714168 & 336.5714027 \\
\hline Ugwuaji & 314.9596212 & 330.8051796 & 326.0766686 \\
\hline Yola & 324.3346392 & 353.624684 & 330.5289031 \\
\hline Damaturu & 323.7185174 & 352.8530294 & 329.9375245 \\
\hline Afam & 330.99 & 330.99 & 330.99 \\
\hline Ikot Ekpene & 323.0078886 & 326.2199304 & 325.6261168 \\
\hline Jebba GS & 339.9 & 339.9 & 339.9 \\
\hline
\end{tabular}

ISSN No:-2456-2165

\begin{tabular}{|c|c|c|c|}
\hline Adiabor & 325.7784075 & 326.4472816 & 326.3236257 \\
\hline Odukpani & 328.02 & 328.02 & 328.02 \\
\hline Alagbon & 337.7406956 & 337.7406956 & 337.7406956 \\
\hline Lekki & 339.5419418 & 339.5419418 & 339.5419418 \\
\hline Owerri & 330.0154721 & 330.0154721 & 330.0154721 \\
\hline Ahoada & 331.2471616 & 331.2471616 & 331.2471616 \\
\hline bus47 & 333.96 & 333.96 & 333.96 \\
\hline Yenogua & 330.4708621 & 330.4708621 & 330.4708621 \\
\hline Aba & 320.9379433 & 315.335863 & 325.5322607 \\
\hline Shiroro & 330 & 330 & 330 \\
\hline ITU & 318.945584 & 309.8996079 & 330 \\
\hline Eket & 321.8144402 & 306.8122637 & 327.204186 \\
\hline Ibom & 327.03 & 0.00033 & 0.00033 \\
\hline oshogbo & 317.9909028 & 322.5048138 & 322.4655611 \\
\hline Ayede & 313.6793088 & 317.158601 & 317.1341359 \\
\hline Ikeja West & 318.5874724 & 322.0601973 & 322.0186589 \\
\hline Ihovbor & 330 & 330 & 330 \\
\hline & & & \\
\hline
\end{tabular}

Table 1

Graphs of the Results

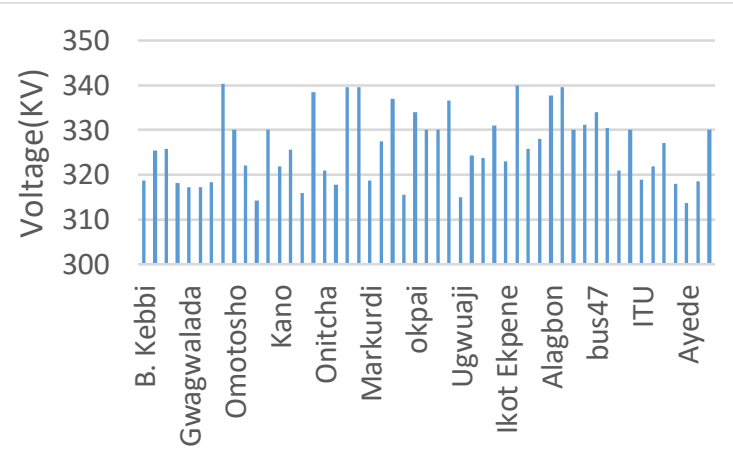

Fig 3:- Graph of Voltage against the Buses on Base Simulation

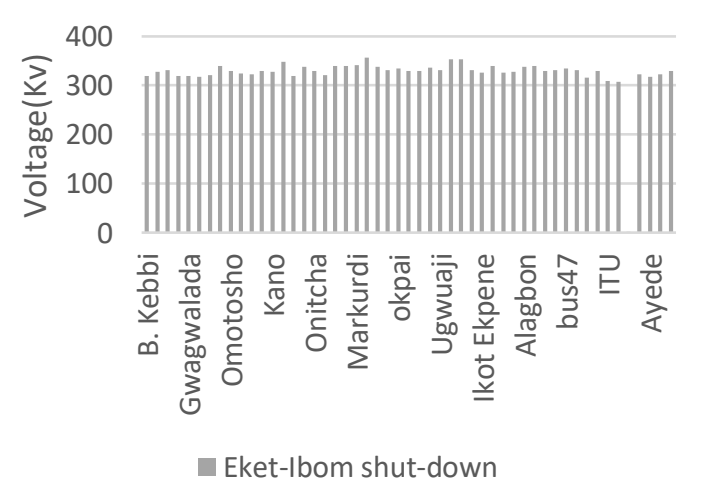

Fig 4:- Graph of Voltage against Buses when Eket=Ibom is shut down 


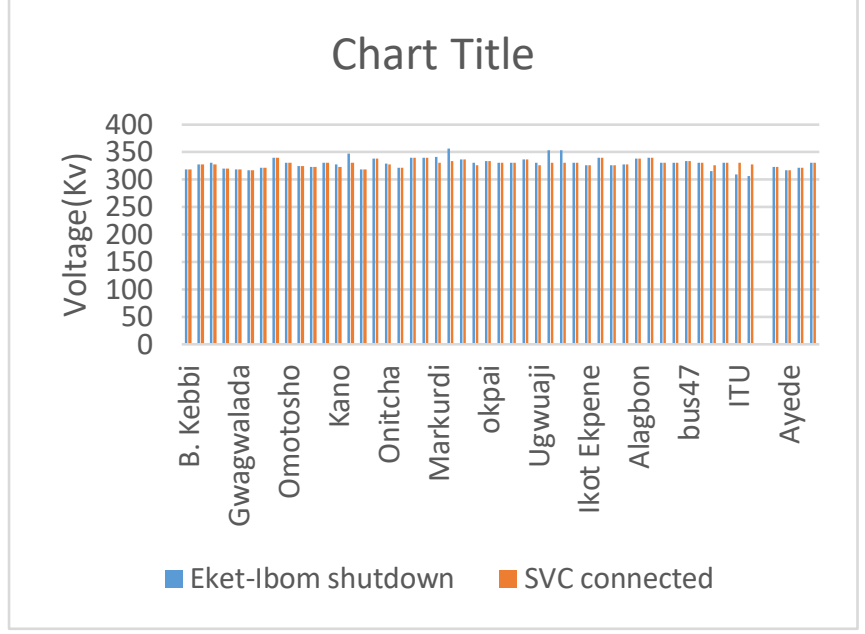

Fig 5:- Graph of Voltage against Buses when Eket-Ibom after Compensation

\section{Discussion of Results/Summary}

The average voltage for base simulation was $326.25 \mathrm{KV}$, during contingency was $323.67 \mathrm{KV}$ and after compensation, it was $322.37 \mathrm{KV}$. Voltage violations were at lower limit were observed at Itu as $309 \mathrm{KV}$ and Eket as $306.81 \mathrm{KV}$ while violations for upper limit were recorded at Damaturu as $352.85 \mathrm{KV}$, Yola as $353.62 \mathrm{KV}$, Gombe as $355.98 \mathrm{KV}$, Jos as $342.97 \mathrm{KV}$. However after shunt compensation there were improvements for the violations at lower limits and that of higher limit were drastically brought down as recorded below thus; Damaturu 329.93 $\mathrm{KV}$, Jos $330 \mathrm{KV}$, Eket 327.2 KV, Gombe 333.55KV, Itu $330 \mathrm{KV}$, and Yola $330.52 \mathrm{KV}$.

The improvement of the voltage profile brings about more power stability and enhance controllability and increase power transfer capability. This has been achieved at the various buses with diferent degrees of violations. There are many constraints as regards to expansion of the grid system in interconnected power systems hence the choice of shunt compensation with static Var compensator (svc) using TCS- FC technique comes to play.

\section{REFERENCES}

[1]. Boudjella, H and Gherbi, F. Z, (2008), "Modelling and Simulation of Static Var compensator (SVC) in Power system studies by MATLAB", ACTA Electrotecnica, Mediamua Science Publisher, Vol 49, No 4

[2]. Grainger, J and Stervenson, W, (1994), "Power System Analysis, New York: Mc Graw- Hill

[3]. Karpagam, N and Deraray, D, (2009), "Fussy Logic Control of Static Var Compensator for Power System Damping", World Academy of Science, Engineering Tech

[4]. Karpagam, N., and Devaraj, D. (2009), Fuzzy Logic control of static VAR compensator forpower system damping, International Journal of Electrical and Electronics Engineering, pp.3-10
[5]. Maduemenem, T.C and Nnonyelu, C. J, (2013), "Power System Contingency Analysis; A study of Nigeria's 330KV Transmission Grid “, a proceeding of Energy source for power

[6]. Onojo, O.J, Ononiwu, G.C and Okozi, S.O, (2013), "Analysis of Power flow of Nigeria 330KV grid System (pre and post) using MATLAB", European Journal of Natural and Applied Science, 1 (2) 59-66

[7]. Oltean, S.E. (2012), Modern control of static var compensator for power system stabilityenhancement,Scientific Bulletin of the „PetruMaior” University of Tîrgu Mureş, vol. 9 (XXVI), no. 1, pp. 33-37.

[8]. Sankarbabu, P and Subrahmanyam J.B.U, (2010), “A novel on Line Fuzzy control method of Static Var compensation for an effective Reactive power control and Transmission lines", ACTA Electrotechnica, Vol 51, No1, pp 45-51 